\title{
THE IMPACT OF TOBACCO CONTROL PROGRAM EXPENDITURES ON AGGREGATE CIGARETTE SALES: 1981-1998
}

\author{
Matthew C. Farrelly \\ Terry F. Pechacek \\ Frank J. Chaloupka \\ Working Paper 8691 \\ http://www.nber.org/papers/w8691 \\ NATIONAL BUREAU OF ECONOMIC RESEARCH \\ 1050 Massachusetts Avenue \\ Cambridge, MA 02138 \\ December 2001
}

The authors would like to thank Andrew Sfekas and Kristin Thomas for excellent programming support, Susan Murchie for editorial assistance, Gary Zarkin for providing helpful suggestions on earlier drafts of this paper, and the Robert Wood Johnson Foundation for research support for Chaloupka through the ImpacTeen project. The views expressed herein are those of the authors and not necessarily those of the National Bureau of Economic Research.

(C) 2001 by Matthew C. Farrelly, Terry F. Pechacek and Frank J. Chaloupka. All rights reserved. Short sections of text, not to exceed two paragraphs, may be quoted without explicit permission provided that full credit, including $(\mathbb{C}$ notice, is given to the source. 
The Impact of Tobacco Control Program Expenditures

on Aggregate Cigarette Sales: 1981-1998

Matthew C. Farrelly, Terry F. Pechacek and Frank J. Chaloupka

NBER Working Paper No. 8691

December 2001

JEL No. I18

\begin{abstract}
Since the 1998 Master Settlement Agreement between states and the tobacco industry, states have unprecedented resources for programs to reduce tobacco use. Decisions concerning the use of these funds will, in part, be based on the experiences of states with existing programs. We review the experiences of several states that have adopted comprehensive tobacco control programs. We also report estimates from econometric analyses of the impact of tobacco control expenditures on aggregate tobacco use in all states and in selected states with comprehensive programs for the period from 1981 through 1998. Our analyses clearly show that increases in funding for state tobacco control programs reduce tobacco use.
\end{abstract}

Matthew C. Farrelly

Health, Social and Economics Research

Research Triangle Institute

3040 Cornwallis Rd.

Research Triangle Park, NC 27709

mcf@rti.org

Frank J. Chaloupka

Department of Economics

University of Illinois at Chicago

601 South Morgan Street

Chicago, IL 60607-7121

and NBER

fjc@uic.edu
Terry F. Pechacek

Office on Smoking and Health

Centers for Disease Control and Prevention

4770 Buford Highway N.E.

Atlanta, GA 30341

tpechacek@cdc.gov 


\section{Introduction}

In the wake of the 1998 Master Settlement Agreement (MSA) between states and the tobacco industry, the states are in a position to allocate settlement dollars for programs aimed at reducing tobacco use. As state policymakers consider whether or not to fund tobacco control programs, many will review the impact of existing state programs on tobacco use. We review the experiences of several states with comprehensive tobacco control programs and perform an analysis of the impact of tobacco control expenditures on aggregate tobacco use in all states before the MSA, from 1981 through 1998.

Historically, funding for tobacco control has come from a variety of sources, including state cigarette excise taxes, appropriations by state legislatures, voluntary organizations (e.g., American Lung Association, American Cancer Society) and federal programs (USDHHS, 2000). During the late 1980s and the 1990s, funding for tobacco control programs in several states increased markedly. In 1988, California voters approved Proposition 99 which raised the cigarette excise tax by 25 cents per pack and used the new revenue to support a statewide tobacco control program that began in 1989 with an annual budget of roughly $\$ 100$ million. In November 1992, Massachusetts voters passed the Question 1 referendum to raise the tobacco tax by 25 cents and created the Massachusetts Tobacco Control Program that began in October of 1993. Arizona voters passed Proposition 200 in 1995, which increased the state cigarette excise tax by 40 cents and funded a tobacco control program. Oregon voters passed Measure 44 in November 1996, which increased the cigarette excise tax by 30 cents and created a tobacco control program that began in July 1997. In June 1997, Maine raised the cigarette excise tax from 37 cents to 74 cents and created its tobacco control program that began in 1998. Recently, 
Alaska, Hawaii, New York and Washington have also substantially raised their cigarette excise taxes.

In addition to excise-tax-funded programs, three national programs have contributed substantial resources to tobacco control, beginning with the Americans' Stop Smoking Intervention Study (ASSIST). In 1990, the National Cancer Institute (NCI) and the American Cancer Society selected 17 states to participate in ASSIST, beginning with 2 years of funding for planning followed by 5 years of funding for tobacco control activities. In 1993, CDC's Office on Smoking and Health (OSH) started the Initiatives to Mobilize for the Prevention and Control of Tobacco Use (IMPACT) program, which funded tobacco control programs in 32 of the 33 remaining states, excluding California. ${ }^{1}$ Lastly, in 1994 the Robert Wood Johnson Foundation (RWJF) began providing additional funding to 19 states through its SmokeLess States program. This number increased to 32 states in 1997 and 40 in 2001.

In addition to these sources of funding, individual state settlements with the tobacco industry (Florida, Minnesota, Mississippi, and Texas) and the MSA, which sets aside \$206 billion for 46 states over 25 years, provide policymakers with substantial funds that could be allocated for programs aimed at reducing tobacco use. These allocation decisions will, in part, be based on the evidence concerning the impact of existing state programs on tobacco use. However, with the exception of one study, analyses of the impact of current programs on tobacco use have focused on trend analyses that do not control for changes in excise taxes, cross-border cigarette sales, and other state-specific factors. In the current study, we analyze time-series data on cigarette demand to evaluate these programs as natural experiments, controlling for other relevant state-specific factors. The results of this study should provide policymakers with more 
complete information on the effectiveness of tobacco control programs as states consider appropriating MSA funds for tobacco control programs.

\section{Overview of Tobacco Control Programs}

A handful of states have invested in large-scale comprehensive, tobacco control programs (USDHHS, 2000; ACSL, 2001). These programs vary considerably from state to state, but they generally include some or all of the following components: $\mathrm{TV}$, radio, and/or print public education campaigns; school-based tobacco prevention programs; smoking cessation materials and telephone "quitlines"; community grants to promote smoking cessation and tobacco control policy change; and enforcement of existing policies aimed at curbing exposure to smoke in public places and access to tobacco by youth. The CDC has produced guidelines, summarized in its "Best Practices for Comprehensive Tobacco Control Programs," that outline specific funding ranges and programmatic recommendations to states for creating comprehensive programs (CDC, 1999). These guidelines resulted from evidence-based analyses of excise tax-funded programs in California and Massachusetts and on the CDC's involvement in the establishment of comprehensive tobacco control programs in Oregon and Maine.

Overall, in fiscal year 1998 , tobacco control funding for all states ranged from $\$ 0.03$ to $\$ 6.35$ per capita, with the larger programs ranging from $\$ 1.59$ to $\$ 6.35$. Because the overall average per capita funding is only $\$ 1.03$, most states are far from CDC guidelines for comprehensive programs of $\$ 5.98$ to $\$ 15.85$ annual per capita funding (CDC, 2001). To assess the impact that these investments have had on tobacco use, we briefly review several state-based studies and one national study.

\footnotetext{
${ }^{1}$ The two federal programs have since merged into the National Tobacco Control Program, based at CDC's Office on Smoking and Health.
} 
With the exception of one national evaluation, most existing evaluations of state programs have focused on changes in tobacco use within a state after the implementation of a tobacco control program. In addition, most of these studies perform trend analyses that do not control for price or tax effects or other potentially confounding factors.

For example, Manley and colleagues (Manley et al., 1997) compared the trends in per capita monthly sales in states participating in the ASSIST program to other states. Their analysis showed that trends in both ASSIST and non-ASSIST states were closely matched in per capita sales until 1993 (when the ASSIST interventions began), at which time sales began to decline faster in the ASSIST states. The data in Figure 1 are similar to those of Manley et al. (1997). Per capita sales declined 28 percent more in non-ASSIST states during this time period. However, whether these results would change if taxes and other factors were considered is not clear.

Several studies summarize the experiences of Arizona, California (Pierce et al., 1998; Hu et al., 1995a, 1995b), Florida (Florida Health Department, 2000), Massachusetts (CDC, 1996; and Connolly and Robbins, 1998), and Oregon (CDC, 1999), which have implemented largescaled programs and experienced declines in tobacco use. With the exception of Hu et al. (1995a, 1995b), these studies focus on differences in univariate trend analyses that compare tobacco use before and after program initiation, as well as changes in tobacco use relative to all other states without similar programs (Figure 2). Whereas per capita sales dropped 15.4 percent for the total U.S. from 1990 to 1999 , the other 4 states dropped 36.9 percent on average. Thus, the evidence is compelling that these programs have reduced tobacco use. Once again, however, these reductions may be confounded by other factors. 
For example, with the exception of Florida, all state programs were funded by increases in cigarette excise taxes. As a result, some of the changes in consumption in Figure 2 are a result of tax changes. Critics of tobacco control programs question whether some or all of these successes resulted from the increases in cigarette prices caused by increases in excise taxes. In addition, some researchers have claimed that tobacco industry promotions were heavily concentrated in states with large-scaled tobacco control programs (Pierce et al., 1998; Balbach and Glantz, 1998).

The results from the trend analysis by Pierce et al. (1998) for California were bolstered by multivariable analyses by $\mathrm{Hu}$ et al. (1995a). Hu and colleagues created an aggregate demand model using quarterly data on per capita cigarette sales from 1980 to 1993 . They then looked for associations between current per capita sales and lagged sales, excise taxes, cigarette prices (less taxes), time, quarterly dummy variables, a dummy variable for the 1983 federal excise tax increase, cigarette advertising, and expenditures on California's anti-smoking campaign. The authors argue that advertising (and in this case, counter-advertising) has a cumulative effect on sales and hence should be treated as a stock variable, rather than a flow variable. As a result, they create a variable that sums all past campaign expenditures and depreciate them by 5 percent, as suggested by McGuinness and Cowling (1975) as the optimal decay rate. This approach alleviates the problem of collinearity across multiple lags; however, the decay function forced on the data may not be borne out in the data.

Hu et al. (1995a) did find that that per capita cigarette sales decreased as anti-tobacco mass media expenditures increased and that a proxy variable for increased cigarette advertising in California was associated with increases in per capita consumption. Using the same data, $\mathrm{Hu}$ 
et al. (1995b) estimated the elasticity of the effect of tobacco control expenditures on per capita consumption to be -0.05 .

\section{Demand Model Specifications}

Our paper builds on the work of $\mathrm{Hu}$ et al. (1995a), on an extensive aggregate cigarette demand literature (e.g. Chaloupka and Saffer, 1992; Evans, Ringel, and Stech, 1999; Baltagi and Levin, 1985; Sung, Hu and Keeler, 1994; and Becker, Grossman and Murphy, 1994), and on a unique historical database of tobacco control program expenditures from all states. We use variation over time and across states in tobacco control program spending to isolate the impact of tobacco control programs on cigarette consumption. Utilizing this natural experiment framework, we estimate linear regressions of per capita cigarette sales on per capita expenditures for tobacco control programs, controlling for cigarette excise taxes, cross-border cigarette sales that result from interstate tax-differentials, time-varying state factors (such as education and income), and state- and year-specific indicator variables.

\section{Controlling for Cross-Border Sales}

The dependent variable in our models, cigarette sales, is based on tax-paid sales. Taxpaid sales in any given state can over- or under-estimate actual consumption as a result of crossborder sales and untaxed sales on Native American reservations or military bases. Cross-border sales can result in relatively low-tax (high-tax) states having tax-paid sales that are higher (lower) than actual consumption in that state. Our controls for cross-border sales are based on the assumption that this type of activity depends on the size of the tax differential between states, the size of border populations, and the distance of these populations to the relatively low-tax state border. 
Chaloupka and Saffer (1992) capture casual or short-distance "smuggling" by creating a measure for the "importing" of cigarettes from nearby low-tax states and an "exporting" measure to capture smuggling from low-tax states to high-tax states. The incentives for short-distance smuggling rise as the difference between the own-tax and the border-tax increases. The authors also assume that the magnitude of short-distance smuggling depends on the size of the population near the border between the states. They define the short-distance import variable for state $i$ as:

$$
\text { Imports }_{\mathrm{i}}=\sum_{\mathrm{j}} \mathrm{K}_{\mathrm{ij}}\left(\text { Price }_{\mathrm{i}}-\text { Price }_{\mathrm{j}}\right)
$$

where $\mathrm{K}_{\mathrm{ij}}$ is the fraction of the population in the higher-price importing state, $\mathrm{i}$, who live in counties within 20 miles of the lower-price, exporting state, $j$. For each state, the sum is taken over all lower price border-states. The short-distance export variable is defined as:

$$
\text { Exports }_{\mathrm{i}}=\sum_{\mathrm{j}} \mathrm{K}_{\mathrm{ji}}\left(\text { Price }_{\mathrm{i}}-\text { Price }_{\mathrm{j}}\right)\left(\mathrm{POP}_{\mathrm{j}} / \mathrm{POP}_{\mathrm{i}}\right)
$$

where $\mathrm{K}_{\mathrm{ji}}$ is the fraction of the population in the higher-price importing state, $\mathrm{j}$, who live in counties within 20 miles of the lower-price exporting state, i. Including the population of the importing state(s) relative to the exporting state captures the effect that the size of border populations can have on sales in the exporting states.

Our adjustment for smuggling diverges from Chaloupka and Saffer (1992) in three ways. First, we use Geographic Information Systems software for calculating all measures of smuggling. This software provides a straightforward method of calculating distances to all state borders and population weights that is useful for calculating measures of the potential for smuggling. For example, we can calculate the distance from the centroid of every census block 
group in a state to the border and use this distance, combined with census block populations, to weight interstate tax differentials. Although most of the smuggling will happen closer to borders (previous studies only examine populations within 20 to 30 miles from a state border), we include all block groups and weight the tax differentials by the inverse of the distance to the border so that populations far from the border will get small weights. Previous estimates relied on calculating distances from counties that can have several population centers.

Second, Chaloupka and Saffer (1992) include a measure to control for the potential of long-distance smuggling from extremely low-tax, tobacco-producing states, such as Virginia, North Carolina, and Kentucky. However, the construct used in Chaloupka and Saffer (1992) is based on price differentials between a given state and these tobacco-producing states. We chose not to include this measure because the primary source of variation in prices is the state tax and taxes in these states did not change between 1981 and 1998 (with the exception of a small change in the tax in North Carolina). As a result, changes in this measure are highly collinear with changes in prices within a given state. In fact, regressing the long-distance smuggling measure on prices and state and year indicator variables explains 98 percent of the variation in the smuggling measure (Farrelly et al., 2000).

Lastly, Chaloupka and Saffer (1992) use prices rather than taxes in their demand model and their smuggling measures. The cigarette demand literature is equivocal on the choice of prices versus taxes. We chose to use cigarette excise taxes for two reasons. First, it is the relevant policy variable that legislators and policymakers can manipulate. Second, we recently learned more about the methods used by the Tobacco Institute to collect cigarette price data at the state level and have concerns about the accuracy of the price estimates. ${ }^{2}$

\footnotetext{
${ }^{2}$ Despite these caveats, our results were not very sensitive to specifications using prices.
} 


\section{Tobacco-Control Expenditures}

The key explanatory variable in our models is the state per capita expenditure on tobacco control (we describe the sources of these data in greater detail below). Characterizing tobacco control programs using expenditure data is challenging given the nature of tobacco control interventions. As described above, tobacco control programs consist of a variety of interventions. Unfortunately, we do not have expenditure data broken out by type of intervention (the majority of tobacco control programs do not track expenditures at this level of detail). Therefore, overall expenditures are a proxy for state tobacco control activities. Furthermore, we cannot distinguish from the aggregate expenditures the expenditures that are for program planning and developing versus those that are for actual program implementation. As a result, expenditures in any given year may not have an impact on tobacco use until subsequent years.

Similarly, some interventions, such as media campaigns and education programs, may initially change attitudes toward tobacco use, which lead to later reductions in tobacco use. For example, in Florida where the tobacco control program was directed at youth, tobacco use did not decline until two years after program implementation. However, attitudes toward tobacco became increasingly negative during the course of the first year of the campaign (Sly, 1999; Bauer et al., 2000; Florida Department of Health, 2000). This phenomenon is consistent with the health behavior literature that states that behavior change is a gradual process consisting of precontemplation, contemplation, action, maintenance, and relapse (Prochaska et al., 1983, 1985, and 1988). As a result, we explore the lag structure of tobacco control expenditures to determine when expenditures in any given year impact overall tobacco consumption. 
Finally, as education and income variables, we use the high school dropout rate and per capita disposable income, both measured at the state level. Combining all of these variables into a demand model yields equation (3) below:

$$
\begin{gathered}
\text { PCCIGSLS }=\mathrm{a}_{0}+\mathrm{a}_{1} * \text { RPCEXP }+\mathrm{a}_{2} * \text { RTAX }+\mathrm{a}_{3} * \text { IMPORT }+\mathrm{a}_{4} * \text { EXPORT }+\mathrm{a}_{5} * \\
\text { RPCDISINC }+\mathrm{a}_{6} * \text { HSDROP }+\mathrm{b} * \text { STATE }+\mathrm{c} * \text { YEAR }+\varepsilon
\end{gathered}
$$

where:

\author{
PCCIGSLS = per capita annual cigarette sales in a state, \\ RPCEXP = real per capita expenditures on tobacco control programs, in dollars, \\ RTAX $=$ the real tax (state + federal) on a pack of cigarettes in the state, in dollars, \\ RPCDSINC = real (1998 dollars) per capita disposable income, in dollars, \\ HSDROP = the state average high school dropout rate, \\ STATE $/$ YEAR $=$ vectors representing and state- and year-specific indicators.
}

For all demand models, we include state indicator variables to ensure that the estimated policy effects reflect an exogenous policy change rather than a combination of the effect of the policy change and some unmeasured characteristic about the state, such as a pro- or anti-tobacco sentiment or social norms within a state. Failing to control for these unobserved characteristics may bias the estimate of the effects of the tobacco control expenditure and tax variables.

\title{
Specifying Tobacco Control Programs
}

To identify the impact of state tobacco control expenditures on state aggregate tobacco use, we take several approaches that reflect both the historical pattern of funding as well as the nature of tobacco control programs. Using crude measures of smoking behavior (i.e., cigarette 
sales) and of tobacco control interventions (i.e., expenditures) complicates evaluations of the impact of these interventions. The models we specify below are an attempt to understand both the immediate and lingering impacts of tobacco control programs on smoking behavior.

We first estimate models that focus on continuous of tobacco control programs based on current year per capita expenditures. Second, to reflect the idea that countermarketing efforts, education programs, and other tobacco control interventions have a gradual effect on behavior, we estimate a demand model with lagged annual expenditures and one with current and lagged annual expenditures. Finally, we construct a measure similar to that created by Hu et al. (1995a) in their evaluation of California's tobacco control program. These authors created a cumulative measure of current and past expenditures, discounting previous periods by 5 percent. This measure is consistent with the notion that tobacco control programs may take time to change tobacco use, but it does force a structure on the lagged variables.

Using all of these more continuous measures of tobacco control, we start with models from 1981 to 1998 that incorporate all states and then re-estimate models incorporating only Arizona, California, Massachusetts, and Oregon, which have been the focus of early evaluation efforts. For all models, we include several years of data before the period when tobacco control programs began in earnest to better establish pre-intervention trends in tobacco consumption. By including a pre-intervention period, we can better isolate the impact of the program on tobacco use.

Finally, as a sensitivity test of the continuous measures of tobacco control programs, we estimate models with dichotomous indicators of tobacco control programs. We accomplish this by creating indicators that are equal to one when the tobacco control program begins or reaches 
critical mass and that equal zero otherwise. These dichotomous indicators reflect whether or not tobacco use declines after program funding reaches critical funding levels.

According to CDC guidelines, minimum adequate funding for a comprehensive tobacco control program begins at $\$ 6$ per capita. Therefore, we created an indicator variable that is equal to 1 if the program reaches that level of funding and that is zero otherwise. However, because only a few programs have reached that level of funding (CDC, 2001), we also created a less ambitious goal (admittedly arbitrary) of $\$ 1$ per capita. One dollar per capita is 10 times the average level of funding for CDC's IMPACT program during the 1990s and is equal to the average funding for FY1998. As a result, we create an indicator variable that complements the comprehensive program goal (\$6 per capita) with an indicator for programs with expenditures between $\$ 1$ and $\$ 5.99$. Finally, we create an indicator variable that is equal to 1 when state funding is greater than or equal to $\$ 1$ and is zero otherwise. Using these indicators, we estimate models with the single indicator for funding greater than or equal to $\$ 1$ per capita and another set of models with two indicators — one for programs with expenditures between $\$ 1$ and $\$ 5.99$ per capita and another for programs with $\$ 6$ or more per capita.

\section{Data Sources}

The key data for our analyses are state aggregate cigarette sales, state and federal cigarette excise taxes, and state-level expenditures on tobacco control programs. Cigarette sales and taxes were obtained from annual volumes of the Tax Burden on Tobacco (The Tobacco Institute, 1998) and are reported corresponding to a July 1 through June 30 fiscal year that is common in states. The sales data for each state were converted to per capita sales using state annual population estimates from the U.S. Census (U.S. Census Bureau, 1998a, 1998b). 
State excise taxes are reported in the Tax Burden on Tobacco (The Tobacco Institute, 1998) as of November 1 of each year; however, the effective date of each tax change is also noted. To create an annual measure of the state tax, we weighted the taxes effective in a given year by the number of months that they are in place. Similarly, state average prices are reported as of November 1. To create prices that correspond to the fiscal year of the consumption data, we weighted the prices accordingly.

Another potentially important state-level factor is the extent of public restrictions on smoking in public places. However, because changing the state and local ordinances restricting public smoking are often a stated goal of tobacco control programs, one can consider them as part of the set of tobacco control interventions. In addition, collecting comprehensive information on all public restrictions for the entire study period is extremely time consuming. Finally, when indicator variables of key restrictions - private and government workplace restrictions - were included in the models, the coefficient on tobacco control expenditures was virtually unchanged. Hence, we chose to not explicitly include the restrictions in our models, allowing the indicators of tobacco control programs and program expenditures to reflect the full array of tobacco control interventions.

We gathered comprehensive data on state tobacco control expenditures from the following sources through state fiscal year 1998 (i.e., June 30, 1998):

- CDC's IMPACT program, which funded 32 states and the District of Columbia from fiscal year (FY) 1994 through FY1998;

- NCI's ASSIST program, which began in FY1991 and included 17 states; 
- RWJF's SmokeLess States program, which eventually funded up to 29 states, and began in FY1994; and

- states with cigarette excise tax-funded, tobacco control programs (e.g., Arizona, California, Massachusetts, and Oregon).

As noted in the introduction, the ASSIST and IMPACT programs complemented one another so that between the two programs, all states (with the exception of California) received federal support for tobacco control interventions by 1994. For states without dedicated funds for tobacco control from excise tax revenue or other sources, these national programs were the primary source of revenue. In Arizona, California, Massachusetts, and Oregon, tobacco control programs are fueled primarily by cigarette excise taxes.

Data for the three national programs were provided to us by CDC, NCI, and RWJF. Although the budgeted amount of funding for these programs tended to change very little year by year, actual expenditures showed a wider range of variation, allowing us to determine more accurately the effects of funding on cigarette consumption. We also obtained information on state excise tax-funded and settlement-funded programs from CDC and from state governments. We have state funding information for Arizona, California, Florida, Maine, Massachusetts, Minnesota, New York, and Oregon.

Other states have also funded tobacco control activities, but their efforts have been limited. The data describing the historical level of effort for programs that have not been funded by the RWJF, CDC, NCI, or one of the large excise tax-funded programs listed above are difficult to obtain. In 1990, 1992, and 1994, the Association for State and Territorial Health Organizations (ASTHO) conducted comprehensive surveys of funding for state tobacco control programs. ASTHO obtained its funding data from telephone surveys of state government 
employees. We compared the data from the ASTHO surveys with the data reported by the major funding sources and selected states and determined that our current tobacco control expenditure database provides comprehensive coverage for all states. ${ }^{3}$

Several states have fiscal years that differ from that of the federal government. We adjusted expenditure data so that all of our data correspond to the reporting period of the per capita cigarette sales (July 1 through June 30) from the Tobacco Institute and the demographic data from the U.S. Census Bureau.

Our models include state- and year-specific indicators. This identification strategy focuses on the correlation between differences in cigarette consumption, taxes and other factors over time within states, effectively making each state its own quasi-experimental control. We believe that this approach leads to stronger causal inference for individual covariates and more accurate predictions of cigarette consumption. Because we rely on changes within states over time, we omitted other factors that did not vary considerably over time, such as the age and racial or ethnic composition of the states.

Income data were obtained from the Bureau of Economic Analysis (U.S. Department of Commerce, 1999), and state high-school dropout rates were derived from the annual March Current Population Survey. Our goal was to estimate our demand models from 1980 through 1998; however, the data on high school dropout rates was only available at the state-level from 1981 through 1998. Hence, all models exclude 1980.

\footnotetext{
${ }^{3}$ During the 1990 s when tobacco control programs became more prominent, we compared our data to the data from the 1990, 1992, and 1994 ASTHO surveys. Differences in average expenditure levels were small, suggesting that apart from the major national programs, little funding was available to states aside from those with dedicated excise tax funds.
} 
Results

The results for the four models of tobacco control program expenditures that include all states indicate that increases in tobacco control program expenditures reduce cigarette sales (Table 2). The results also suggest that this relationship is strongest one year after the expenditures are made. Annual expenditures are statistically significant at the ten percent level, whereas the lagged annual expenditures are statistically significant at the five percent level. Both specifications produce an elasticity of -0.0006 .

Overall, this elasticity may appear to be low, but over the course of several years, programs may have substantial increases in per capita funding for tobacco control. Between 1988 and 1998, overall per capita expenditures for tobacco control increased by 5,650 percent nationwide. Based on the estimated elasticity, sales over those ten years would be expected to decline by three percent whereas cigarette sales actually declined by 17 percent. Considering that states allocating a large portion of their MSA funding to tobacco control would experience substantial increases in funding, these findings suggest that such increases would lead to substantial declines in aggregate tobacco use.

Although neither the coefficient on current or lagged expenditures in specification (model 3) is statistically significant, the pattern of the coefficients supports the idea that the driving force behind the changes in consumption is lagged expenditures. Finally, we specify cumulative expenditures, following $\mathrm{Hu}$ et al. (1995a) and find that the elasticity is nearly twice that for annual expenditures. One way to interpret cumulative expenditures is that it captures the cumulative effects of expenditures in both current and lagged periods in one construct. Considered together, models one through three illustrate that the variation in expenditure levels within states over time may not be sufficient to identify how the effects are distributed over time. 
As a result, the cumulative measure is an alternative method for capturing the current and past effects of tobacco control interventions and avoids collinearity of multiple lag terms. Again, however, discounting past expenditures by a fixed rate forces a lag structure on the data that may not be borne out in the data.

The tax elasticity is robust, equaling -0.22 across the four all-state models. Converting this figure to a price elasticity by examining the effect of tax changes on price over this time period yields a price elasticity of $-0.59 .^{4}$ The extensive literature on the effect of changes in cigarette prices and taxes has been recently summarized by Evans, Ringel, and Stech (1999) and by Chaloupka and Warner (2000). Evans, Ringel, and Stech (1999) used a variety of databases, including a database of state-aggregate cigarette sales, and found that the cigarette price elasticity of demand is -0.30 . This result is similar to those in other recent studies (CDC, 1998; Evans and Farrelly, 1998).

Controls for cross-border sales are stable across all specifications and are consistent with the hypothesized signs — states with taxes that are relatively high (low) compared to neighboring states have lower (higher) tax-paid sales, because residents can purchase in neighboring states. Both higher per capita incomes and high school dropout rates are associated with lower aggregate sales. These results are similar to those from individual-level models where higher incomes are associated with lower consumption, but where higher levels of education are normally associated with lower, not higher, consumption (Farrelly et al, 2001). However, these aggregate measures of socio-economic status may be proxies for other factors not captured in the model. 
To explore how the results from four key states with comprehensive tobacco control programs may differ from states overall, we repeat our four specifications in for Arizona, California, Massachusetts, and Oregon in Table 2. The pattern of results for these states is qualitatively similar to the models with all states, where the strongest relationship is between consumption and expenditures lagged one year. Expenditures are statistically significant at the ten percent level in specification (5), statistically significant at the five percent level in specifications (6) and (7), and at the one percent level in the specification (8). The results from these key states are striking because the expenditure elasticities are roughly 10 to 50 times as great as the models with all states. These results suggest that tobacco control programs are more effective, dollar for dollar, when implemented on a larger scale.

The elasticities for tobacco control expenditures in the models of current and lagged annual expenditures are roughly the same, -0.006 and -0.007 , respectively. However, the elasticity for cumulative expenditures is considerably higher in model 8 , at -0.025 , suggesting that expenditures in past years have an important impact on current consumption. The tax (price) elasticity of the cumulative expenditures specification is $-0.17(-0.46)$ and is statistically significant. However, in the other three specifications, the coefficient on tax is not statistically significant. The same is true for many of the other state-level factors in this 4-state regression, most likely because of insufficient variation within states over time. The results of similar models using all states provide more precise estimates of all variables.

We assessed the dichotomous indicators of tobacco control with equation (3), including data from all states from 1981 through 1998 and with several indicators of tobacco control

\footnotetext{
${ }^{4}$ Because prices are a function of taxes, the impact of taxes on demand is represented by $\partial \mathrm{y} / \partial \mathrm{t}=(\partial \mathrm{y} / \partial \mathrm{p}) /(\partial \mathrm{p} / \partial \mathrm{t})$. Therefore, $\partial \mathrm{y} / \partial \mathrm{p}=(\partial \mathrm{y} / \partial \mathrm{t}) /(\partial \mathrm{p} / \partial \mathrm{t})$, where $\mathrm{y}=$ cigarette consumption, $\mathrm{p}=$ cigarette prices, and $\mathrm{t}=$ cigarette taxes.
} 
capacity (Table 3). Model 9 uses only the indicator for programs with at least $\$ 1$ per capita funding. Model 10 includes two program expenditure indicators — one for programs with expenditures between $\$ 1$ and $\$ 6$ per capita and another for programs spending at least $\$ 6$ per capita. In models 11 and 12, we lag the program indicators to test whether or not the effects of the program are larger one year after implementation.

The results across all four models provide consistent evidence that tobacco control programs have decreased aggregate tobacco use, controlling for the effects of cigarette excise taxes and other state-level factors. Models 9 and 11 indicate that programs securing at least $\$ 1$ in per capita funding have lower per capita sales and that this effect is larger one year after the program reaches this level of funding. These results are consistent with the notion that tobacco control interventions take time to change behavior. Furthermore, model 10 indicates that comprehensive programs funded above $\$ 6$ in per capita expenditures may result in greater declines in tobacco use. However, this difference is not statistically significant. In addition, once we lag both expenditure indicators (model 12), the coefficient on programs with funding levels of $\$ 1$ to $\$ 6$, becomes larger than that of our lagged indicator for comprehensive programs.

Therefore, although these indicators do not provide a clear pattern of greater declines among comprehensive programs, they do provide additional evidence that tobacco control programs decrease aggregate tobacco use. These indicators are also relatively crude measures of the effect of program size and comprehensiveness on tobacco use, however.

Finally, to explore how spending for tobacco control may impact states with varying levels of tobacco consumption, we performed a series of quantile regressions. As opposed to

Regressing real prices on real taxes and state and year indicator variables to estimate ( $\partial \mathrm{p} / \partial \mathrm{t})$ from 1981-1998 yields a value of 1.25 . 
regression through the mean, as in ordinary least-squares regression, quantile regression involves minimizing the differences from a quantile of interest (e.g., median). Making use of the entire distribution, these regressions can indicate whether excise taxes and tobacco control expenditures have a larger or smaller impact when tobacco consumption is relatively high (i.e., in the $75^{\text {th }}$ percentile).

We began our quantile regressions using the same models used in Table 2. However, our models that included state and year effects did not converge at all of the various quantiles of interest. As a result, we reduced the number of indicators to be estimated by including indicators for 9 census regions, rather than state indicator variables. We present the ordinary least square results of this specification in the first column of Table 4 for comparison with the results in Table 2. These results indicate that the price and expenditure elasticities are higher when we do not control for state indicator variables.

The results from the quantile regressions (Table 4) indicate that increases in tobacco control expenditures (whether specified as cumulative or lagged annual expenditures) have their greatest impact when aggregate tobacco use is relatively high. From the lowest to the highest quantile, the impact of expenditures grows monotonically for lagged annual expenditures (from 0.0004 to -0.0037 ) and nearly monotonically for cumulative expenditures (from -0.0009 to 0.0048). In contrast, the effect of taxes varies little across the distribution of cigarette consumption.

\section{Discussion}

With the exception of $\mathrm{Hu}$ et al. (1995a, 1995b), studies have examined the impact of state tobacco control programs on cigarette consumption by relying on univariate trend analyses (Pierce et al., 1998; Florida Department of Health, 2000; CDC, 1996; Connolly and Robbins, 
1998; CDC, 1999). In addition, in reviewing the evidence on the effectiveness of comprehensive tobacco control programs, the recent Surgeon General's Report on Reducing Tobacco Use concluded that comprehensive tobacco control programs work. Although these studies have consistently suggested that state tobacco control programs decrease tobacco use, these studies could have easily been confounded by changes in excise taxes, cross-border sales, and other factors. The various models presented in this paper, which control for these confounding factors, reinforce the findings from the individual state trend analyses and provide strong evidence that tobacco control programs are effective. 


\section{References}

Baltagi, B., and Levin, D., 1985. Estimating dynamic demand for cigarettes using panel data: the effects of bootlegging, taxation and advertising reconsidered. The Review of Economics and Statistics 69(4):148-155.

Bauer, U.E., Johnson, T.M., Hopkins, R.S., Brooks, RG., 2000. Changes in youth cigarette use and intentions following implementation of a tobacco control program: findings from the Florida Youth Tobacco Survey, 1998-2000. JAMA 284(6):723-728.

Becker, G.S., Grossman, M., Murphy, K.M., 1994. An empirical analysis of cigarette addiction. The American Economic Review 84(3):396-417.

Centers for Disease Control and Prevention (CDC), 1996. Cigarette smoking before and after an excise tax increase and an antismoking campaign-Massachusetts, 1990-1996. Morbidity and Mortality Weekly Report 45(44):966-970.

Centers for Disease Control and Prevention (CDC), 1998. Response to increases in cigarette prices by race/ethnicity, income, and age groups_-United States, 1976-1993. Morbidity and Mortality Weekly Report 47(29):605-609.

Centers for Disease Control and Prevention (CDC), 1999. Decline in Cigarette Consumption Following Implementation of a Comprehensive Tobacco Prevention and Education Program - Oregon, 1996-1998. Morbidity and Mortality Weekly Report 48(7):140-143.

Centers for Disease Control and Prevention (CDC), Office on Smoking and Health, 2001. Investment in Tobacco Control - State Highlights 2001. http: \www.cdc.gov.tobacco/statehi_2001.htm.

Chaloupka, F.J., Saffer, H., 1992. Clean indoor air laws and the demand for cigarettes. Contemporary Policy Issues 10(20:72-83.

Chaloupka, F.J., Warner, K.E., 2000. The economics of smoking, in: Newhouse, J.P., Cuyler, A.J. (Eds.), The Handbook of Health Economics, North-Holland, . New York, pp. 15391627. Also available as: The National Bureau of Economic Research Working Paper Series (No. 7047).

Connolly, G., Robbins, H., 1998. Designing an effective statewide tobacco control programMassachusetts. CANCER Supplement 83(12):2722-2727.

Evans, W.N., Farrelly, M.C., 1998. The compensating behavior of smokers: taxes, tar, and nicotine. The Rand Journal of Economics 29:578-595.

Evans, W.N., Ringel, J and Stech, D., 1999. Tobacco Taxes and Public Policy to Discourage Smoking. Tax Policy and the Economy: Vol. 13, Edited by James Poterba, Cambridge, MA: National Bureau of Economic Research. 
Farrelly, M.C., Davis, K.C., Nimsch, C.T., Hanchette, C.L., 2000. Cigarette smuggling revisited. Presentation to Western Economic Association Meetings, Vancouver, BC, July, 2000.

Farrelly, M.C., Bray, J.W., Pechacek, T, and Woollery, T., 2001. Response by Adults to Increases in Cigarette Prices by Sociodemographic Characteristics. Southern Economic Journal 68(1):156-165.

Florida Department of Health, 2000. Florida Youth Tobacco Survey Reports: 2000; Florida Youth Tobacco Survey results. Florida Department of Health, Bureau of Epidemiology.

Hu, T.-W., Sung, H.-Y., Keeler, T.E., 1995a. The state antismoking campaign and the industry response: the effects of advertising on cigarette consumption in California. American Economics Association Papers and Proceedings 85(2):85-90.

Hu, T.-W., Sung, H.-Y., Keeler, T.E., 1995b. Reducing cigarette consumption in California: tobacco taxes vs. an anti-smoking media campaign. American Journal of Public Health 85(9):1218-1222.

Manley, M.W., Pierce, J.P., Gilpin, E.A., Rosbrook, B., Berry, C., Wun, L-M., 1997. Impact of the American Stop Smoking Intervention Study on cigarette consumption. Tobacco Control 6(Suppl 2):S12-S16.

McGuinness, T., Cowling, K., 1975. Advertising and the aggregate demand for cigarettes. European Economic Review 6:311-28.

Pierce, J.P., Gilpin, E.A., Emery, S.L., White, M.M., Rosbrook, M.S., Berry, C.C., 1998. Has the California Tobacco Control Program reduced smoking? Journal of the American Medical Association 280(10):893-899.

Prochaska, J.O., DiClemencente, C.C., 1983. Stages in processes of self-change of smoking: toward an integrative model of change. Journal of Consulting and Clinical Psychology, No-3, 390-395.

Prochaska, J.O., DiClemencente, C.C., Velicer, W.F., Ginpil, S., Norcross, J.C., 1985. Predicted changes in smoking status for self-changers. Addictive Behavior 10:395-406.

Prochaska, J.O., Velicer, W.F., DiClemente, C.C., Fava, J., 1988. Measuring processes of change: application to the cessation of smoking. Journal of Consulting and Clinical Psychology 56:520-528.

Sly, D.F., Heald, G., 1999. Florida Anti-tobacco media evaluation: eighteen month assessment. Florida State University.

Sung, H-Y., Hu, T-W., Keeler, T.E., 1994. Cigarette taxation and demand- an empirical analysis. Contemporary Economic Policy 12(3):91-100.

The Tobacco Institute, 1998. Tax Burden Tobacco, Historical Compilation. Vol. 32. Washington, DC: The Tobacco Institute. 
U.S. Census Bureau, 1999a. http://www.census.gov/population/estimates/state/ST9097.txt.

U.S. Census Bureau, 1999b. http://www.census.gov/population/estimates/st_sasrh.thml.

U.S. Department of Commerce, Bureau of Economic Analysis, 1999. http://www.bea.doc.gov/bea/dr/spitbl-e.htm.

U.S. Department of Health and Human Services (DHHS), 2000. Reducing Tobacco Use: A Report of the Surgeon General. Atlanta, GA: U.S. Department of Health and Human Services, Centers for Disease Control and Prevention, National Center for Chronic Disease Prevention and Health Promotion, Office on Smoking and Health. 
Table 1. Descriptive Statistics, 1981-1998

\begin{tabular}{lc}
\hline \multicolumn{1}{c}{ Variable } & $\begin{array}{c}\text { Mean } \\
\text { (Standard Deviation) }\end{array}$ \\
\hline Per Capita Cigarette Sales & 108.80 \\
& $(27.59)$ \\
Real Per Capita Funding & $\$ 0.18$ \\
& $(0.95)$ \\
Real Cigarette Taxes & $\$ 0.50$ \\
Per Capita Disposable Income & $\$ 15,594.15$ \\
& $(4,877.91)$ \\
Percent High School Dropouts & 24.0 \\
& $(7.7)$ \\
Weighted Tax Differential-Imports & 0.014 \\
& $(0.064)$ \\
Weighted Tax Differential-Exports & 0.015 \\
& $(0.026)$ \\
\hline
\end{tabular}




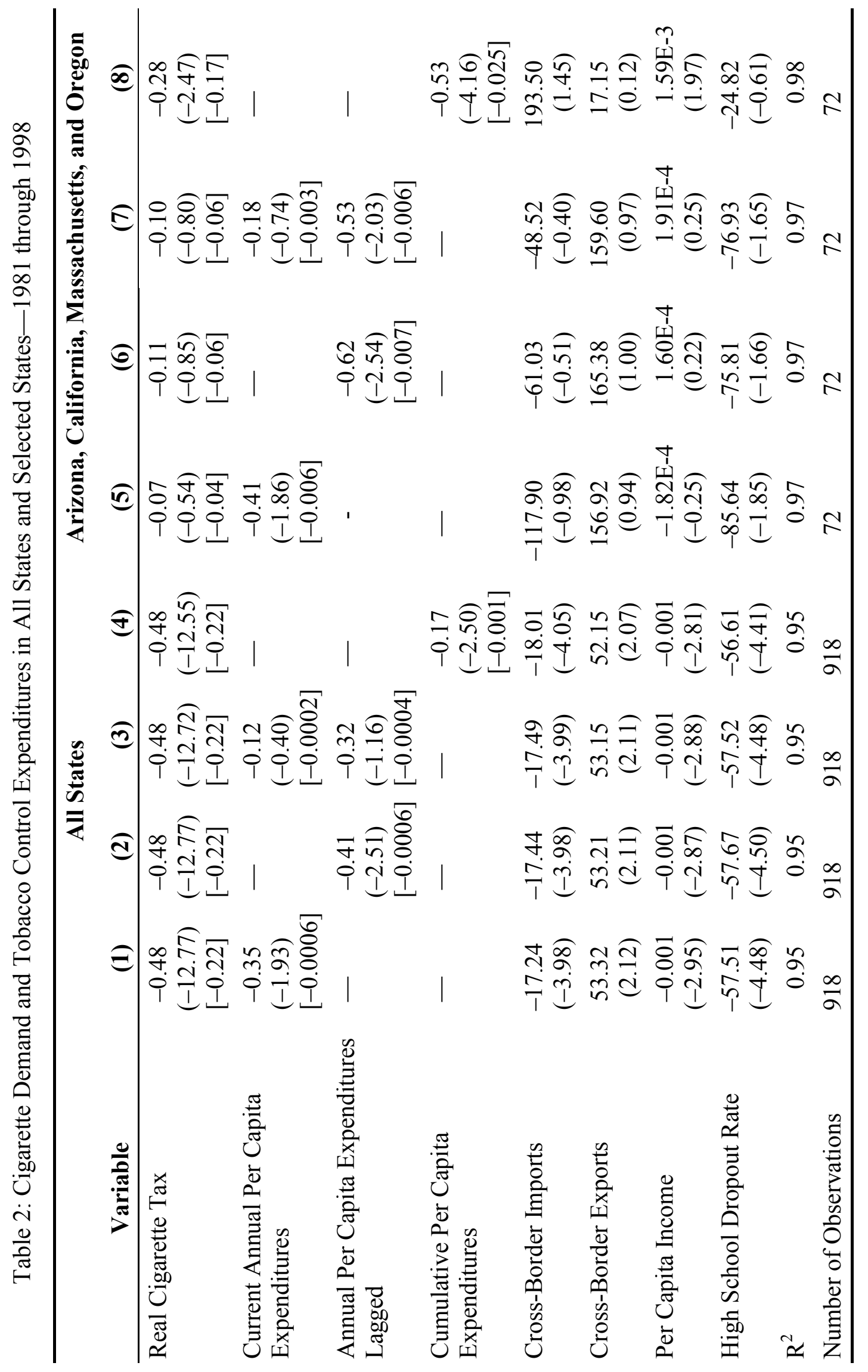


Table 3: Cigarette Demand and Discrete Measures of Tobacco Control Programs-1981 through 1998

\begin{tabular}{lcccc}
\hline \multicolumn{1}{c}{ Variable } & \multicolumn{2}{c}{ Current Year Indicators } & \multicolumn{2}{c}{ Indicators Lagged One Year } \\
& $\mathbf{( 9 )}$ & $\mathbf{( 1 0 )}$ & $\mathbf{( 1 1 )}$ & $\mathbf{( 1 2 )}$ \\
\hline Real Cigarette Tax & -0.47 & -0.47 & -0.47 & -0.47 \\
& {$[-0.22]$} & {$[-0.22]$} & {$[-0.22]$} & {$[-0.22]$} \\
Per Capita Expenditures & $(-12.46)$ & $(-12.44)$ & $(-12.44)$ & $(-12.45)$ \\
\$1 & -3.78 & - & -5.77 & - \\
Per Capita Expenditures & $-2.43)$ & & $(-3.56)$ & \\
between \$1 and \$6 & - & -3.43 & - & -6.32 \\
Per Capita Expenditures & - & $(-1.79)$ & & $(-3.05)$ \\
\$\$6 & & -4.73 & -4.49 \\
Cross-Border Imports & -17.91 & $(-2.51)$ & & $(-2.31)$ \\
& $(-4.08)$ & $(-4.06)$ & $(-4.17)$ & $(-4.12)$ \\
Cross-Border Exports & 52.56 & 52.39 & 53.20 & 53.43 \\
& $(2.09)$ & $(2.08)$ & $(2.12)$ & $(2.13)$ \\
Per Capita Income & -0.001 & -0.001 & -0.001 & -0.001 \\
& $(-3.01)$ & $(-2.89)$ & $(-2.95)$ & $(-2.94)$ \\
High School Dropout Rate & -55.57 & -55.86 & -55.44 & -55.14 \\
R & $(-4.32)$ & $(-4.31)$ & $(-4.34)$ & $(-4.31)$ \\
Number of Observations & 918 & 0.95 & 0.95 & 0.95 \\
\hline
\end{tabular}


Table 4. Quantile Regressions of Cigarette Demand: 1981 through 1998 Model with Regional Effects (9 Census Regions)

\begin{tabular}{lcccccc}
\hline & & \multicolumn{5}{c}{ Quantile } \\
\cline { 3 - 7 } \multicolumn{1}{c}{ Variable } & OLS* & $\mathbf{0 . 1}$ & $\mathbf{0 . 2 5}$ & $\mathbf{0 . 5}$ & $\mathbf{0 . 7 5}$ & $\mathbf{0 . 9}$ \\
\hline Real Cigarette Tax & -0.88 & -0.97 & -0.88 & -0.79 & -0.76 & -0.80 \\
& $(-15.41)$ & $(-28.40)$ & $(-24.28)$ & $(-14.58)$ & $(-9.13)$ & $(-7.18)$ \\
& {$[-0.40]$} & {$[-0.45]$} & {$[-0.40]$} & {$[-0.36]$} & {$[-0.35]$} & {$[-0.37]$} \\
Real Annual & -1.25 & -0.29 & -0.54 & -1.03 & -1.70 & -2.73 \\
Expenditures & $(-4.06)$ & $(-1.03)$ & $(-1.86)$ & $(-1.98)$ & $(-4.21)$ & $(-7.10)$ \\
Lagged & {$[-0.0017]$} & {$[-0.0004]$} & {$[-0.0007]$} & {$[-0.0014]$} & {$[-0.0023]$} & {$[-0.0037]$} \\
$\mathrm{R}^{2} /$ Pseudo R & 0.70 & 0.55 & 0.52 & 0.48 & 0.47 & 0.52 \\
\hline Real Cigarette Tax & -0.88 & -0.96 & -0.88 & -0.79 & -0.76 & -0.80 \\
& $(-15.36)$ & $(-29.59)$ & $(-23.80)$ & $(-17.42)$ & $(-9.11)$ & $(-7.27)$ \\
Real Cumulative Per & -0.37 & -0.15 & -0.28 & -0.44 & -0.40 & -0.65 \\
Capita Expenditures & $(-3.20)$ & $(-1.82)$ & $(-2.59)$ & $(-3.49)$ & $(-3.57)$ & $(-5.83)$ \\
$\mathrm{R}^{2} /$ Pseudo R & {$[-0.0023]$} & {$[-0.0009]$} & {$[-0.0017]$} & {$[-0.0027]$} & {$[-0.0024]$} & {$[-0.0048]$} \\
\hline Number of & $0.70]$ & {$[-0.44]$} & {$[-0.40]$} & {$[-0.36]$} & {$[-0.35]$} & {$[-0.37]$} \\
Observations & 918 & 918 & 918 & 918 & 918 & 918 \\
\hline
\end{tabular}

*Ordinary least-squares regression. 
Figure 1: Per Capita Cigarette Sales: ASSIST vs. Non-ASSIST States 1990-1999, Excluding California

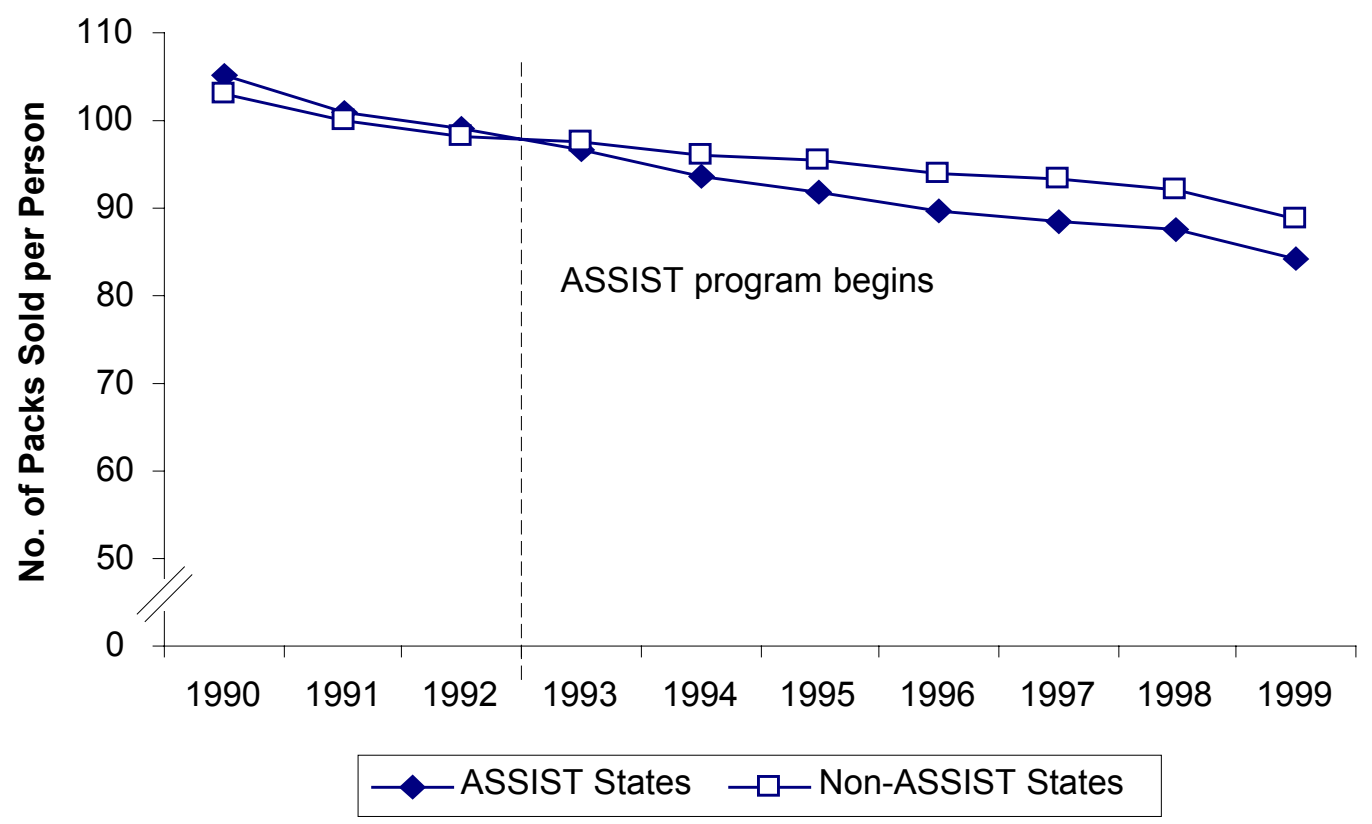


Figure 2: Aggregate Trends in Per Capita Cigarette Sales: 1990-1999

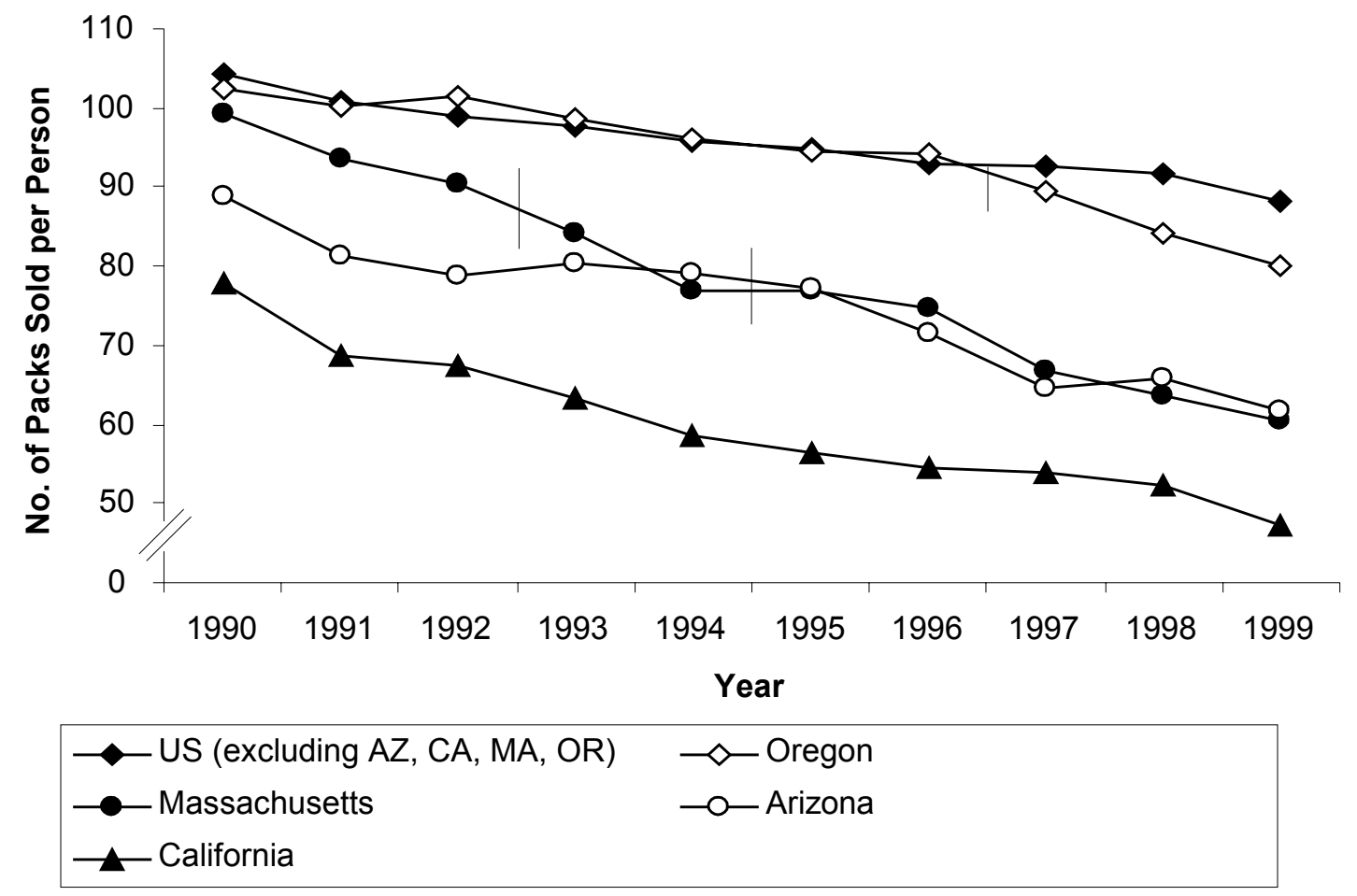

